\title{
Midbrain Dopamine Neurons: Projection Target Determines Action Potential Duration and Dopamine $\mathrm{D}_{2}$ Receptor Inhibition
}

\author{
Elyssa B. Margolis, ${ }^{1}$ Jennifer M. Mitchell, ${ }^{1}$ Junko Ishikawa, ${ }^{1}$ Gregory 0. Hjelmstad, ${ }^{1,2}$ and Howard L. Fields ${ }^{1,2}$ \\ ${ }^{1}$ Ernest Gallo Clinic and Research Center, University of California, San Francisco, Emeryville, California 94608, and ${ }^{2}$ Department of Neurology and Wheeler \\ Center for the Neurobiology of Addiction, University of California, San Francisco, California 94143-0114
}

\begin{abstract}
Broad action potentials (APs) and dopamine $(\mathrm{DA}) \mathrm{D}_{2}$ receptor $\left(\mathrm{D}_{2} \mathrm{R}\right)$-mediated inhibition are widely used to identify midbrain $\mathrm{DA}$ neurons. However, when these measures are taken alone they do not predict DA content in ventral tegmental area (VTA) neurons. In fact, some VTA neuronal properties correlate better with projection target than neurotransmitter content. Here we report that amygdala (AMYG)-projecting VTA DA neurons have brief APs and lack $\mathrm{D}_{2} \mathrm{R}$ agonist (quinpirole; $1 \mu \mathrm{M}$ ) autoinhibition. However, they are hyper-

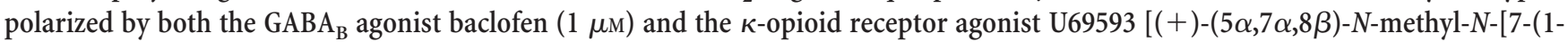
pyrrolidinyl)-1-oxaspiro[4.5]dec-8-yl]benzeneacetamide; $1 \mu \mathrm{m}$ ]. Furthermore, we show that accurate prediction of DA content in VTA neurons is possible when the projection target is known: in both nucleus accumbens- and AMYG-projecting neural populations, AP durations are significantly longer in DA than non-DA neurons. Among prefrontal cortex-projecting neurons, quinpirole sensitivity, but not AP duration, is a predictor of DA content. Therefore, in the VTA, AP duration and inhibition by $\mathrm{D}_{2} \mathrm{R}$ agonists may be valid markers of DA content in neurons of known projection target.
\end{abstract}

Key words: dopamine; ventral tegmental area; nucleus accumbens; amygdala; $\mathrm{D}_{2}$ receptor; $\kappa$-opioid

\section{Introduction}

Many midbrain neurons fire in response to unexpected rewards and reward-predictive cues and in a pattern consistent with a reward prediction error signal (Hyland et al., 2002; Bayer and Glimcher, 2005; Roesch et al., 2007; Schultz, 2007). These firing patterns have been attributed to dopamine (DA) neurons. These in vivo studies generally use two properties to identify substantia nigra pars compacta (SNc) and ventral tegmental area (VTA) neurons as DAergic: action potential (AP) duration and dopamine $D_{2}$ receptor $\left(D_{2} R\right)$ agonist-induced inhibitions. However, in the VTA, physiological studies in which neurotransmitter content has been directly determined indicate that these measures are not reliable markers for DA content either in vivo or in vitro (Johnson and North, 1992; Ungless et al., 2004; Margolis et al., 2006b; Luo et al., 2008).

Midbrain DA neurons were first investigated in the SNc. Grace and Bunney (1980) and Grace and Onn (1989) confirmed that long-duration APs are a property of SNc DA neurons by cytochemically identifying neurons after both in vivo and in vitro intracellular recordings. In addition, DA, but not non-DA, neu-

Received April 8, 2008; revised July 25, 2008; accepted Aug. 4, 2008.

This work was supported by funds provided by the state of California for medical research on alcohol and substance abuse through the University of California, San Francisco. We thank Hagar Lock, Leah Grossman, and Joseph Driscoll for their technical assistance.

Correspondence should be addressed to Elyssa B. Margolis, Ernest Gallo Clinic and Research Center, 5858 Horton Street, Suite 200, Emeryville, CA 94608. E-mail: elyssam@gallo.ucsf.edu.

DOI:10.1523/JNEUROSCI.1526-08.2008

Copyright $\odot 2008$ Society for Neuroscience $\quad$ 0270-6474/08/288908-06\$15.00/0 rons in the SNc are inhibited by activation of somatodendritic $\mathrm{D}_{2}$ Rs (Bunney et al., 1973a,b; Groves et al., 1975; Aghajanian and Bunney, 1977; Lacey et al., 1987, 1989). These properties have made it possible to reliably identify SNc DA neurons in vivo.

Although the SNc and VTA are anatomically contiguous structures, there are important differences between them. In the SNc, $88 \%$ of the neurons are DAergic (Margolis et al., 2006b) (but see Nair-Roberts et al., 2008), and all of these neurons send collaterals to multiple brain regions (Fallon, 1981; Prensa and Parent, 2001). In contrast, only $60 \%$ of VTA neurons are DAergic (Swanson, 1982; Margolis et al., 2006b; Nair-Roberts et al., 2008), and few VTA neurons project to more than one forebrain region (Deniau et al., 1980; Fallon, 1981; Swanson, 1982; Margolis et al., 2006a). Learning and performance of behavioral tasks are also differentially influenced by SNc and VTA (Alderson et al., 2006; Ikemoto et al., 2006; El-Amamy and Holland, 2007).

In addition to their distinct anatomy and behavioral function, the earliest studies of VTA neurons indicated that AP duration and $\mathrm{D}_{2} \mathrm{R}$ sensitivity might not generalize to identify neurons as dopaminergic in this brain region (Johnson and North, 1992). In fact, studies of VTA neurons that use direct methods to determine neurotransmitter content have not identified consistent electrophysiological properties that can predict DA content (Jones and Kauer, 1999; Korotkova et al., 2003; Margolis et al., 2003, 2006b; Ungless et al., 2004; Luo et al., 2008).

Because individual VTA neurons project to only one forebrain target, we tested the hypothesis that $\mathrm{AP}$ duration and $\mathrm{D}_{2} \mathrm{R}$ mediated inhibition are correlates of projection target. We exam- 
ined VTA neurons projecting to the nucleus accumbens (NAc), prefrontal cortex (PFC), or amygdala (AMYG). We show here that AP duration correlates with DA content in NAc- and AMYG-projecting neurons, but not PFC-projecting neurons, and $\mathrm{D}_{2} \mathrm{R}$ inhibition correlates well with DA content only among PFC-projecting neurons.

\section{Materials and Methods}

All experiments conformed to National Institutes of Health and Ernest Gallo Clinic and Research Center animal care policy standards.

Retrograde tracer injections. Male Sprague Dawley rats (27-29 d) were anesthetized with isoflurane. A $1 \mu$ Hamilton syringe was stereotaxically placed in the PFC [from bregma (in $\mathrm{mm}$ ): anteroposterior, +2.6 ; mediolateral (ML), \pm 0.8 ; ventral $(\mathrm{V}),-4.0$ from skull surface], the NAc (anteroposterior, $+1.5 ; \mathrm{ML}, \pm 0.8 ; \mathrm{V},-6.7$ ), or AMYG (anteroposterior, -1.0 ; ML, $\pm 4.5 ; \mathrm{V},-8.0$ ). Neuro-DiI (7\% in ethanol; Biotium) was slowly injected, $0.3-1.0 \mu \mathrm{l}$ per side. A small set of AMYG injections were completed in older (mean, $200 \pm 5 \mathrm{~g}$; range, 180-240 g) rats (anteroposterior, $-2.2 ; \mathrm{ML}, \pm 4.8 ; \mathrm{V},-8.5)$. After recordings, all injection sites were histologically confirmed (supplemental Fig. 1, available at www.jneurosci.org as supplemental material). Animals with improper injection placements or significant diffusion outside of the target regions were rejected.

Slice preparation and electrophysiology. A subset of recordings were made in control male Sprague Dawley rats (25-40 d). Most recordings in retrogradely labeled neurons were made blind to injection site, 6-8 d after surgery. A subset of data shown in Figure 1 was obtained from a previous study (Margolis et al., 2006b). Horizontal brain slices (150 $\mu \mathrm{m}$ thick) were prepared using a vibratome (Leica Instruments). Slices were prepared in ice-cold Ringer's solution (in mM: $119 \mathrm{NaCl}, 2.5 \mathrm{KCl}, 1.3$ $\mathrm{MgSO}_{4}, 1.0 \mathrm{NaH}_{2} \mathrm{PO}_{4}, 2.5 \mathrm{CaCl}_{2}, 26.2 \mathrm{NaHCO}_{3}$, and 11 glucose saturated with $95 \% \mathrm{O}_{2}-5 \% \mathrm{CO}_{2}$ ) and allowed to recover at $35^{\circ} \mathrm{C}$ for at least $1 \mathrm{~h}$. Slices were visualized under a Zeiss Axioskop with differential interference contrast optics and infrared, and epifluorescent illumination to visualize DiI-labeled neurons. Whole-cell recordings were made at $33^{\circ} \mathrm{C}$ using 2.5-4 $\mathrm{M} \Omega$ pipettes containing the following (in $\mathrm{mM}$ ): 123 K-gluconate, 10 HEPES, 0.2 EGTA, $8 \mathrm{NaCl}, 2 \mathrm{MgATP}, 0.3 \mathrm{Na}_{3} \mathrm{GTP}$, and $0.1 \%$ biocytin ( $\mathrm{pH} 7.2$, osmolarity adjusted to 275 ). Liquid junction potentials were not corrected during recordings.

Recordings were made using an Axopatch 1-D (Molecular Devices), filtered at $2 \mathrm{kHz}$ and collected at $5 \mathrm{kHz}$ using IGOR Pro (WaveMetrics). In control animals, VTA neurons were selected in an unbiased manner from throughout the VTA by superimposing a grid on the slice, numbering each grid location, and using a random number generator to choose the grid location for recording. The closest healthy cell to the randomly generated grid location was patched. In all cases, APs were collected by holding the cell in current clamp at $I=0$, and only spontaneously occurring APs were measured within the first 2 min of gaining whole-cell access. Neurons were required to be firing spontaneously and stably for at least $2 \mathrm{~min}$ with firing rates $>0.25 \mathrm{~Hz}$ to be included in the firing data.

Agonists, antagonists, ATP, GTP, and all other chemicals were obtained from Sigma or Tocris Bioscience.

Identification of DA neurons. Slices were fixed immediately after recording in $4 \%$ formaldehyde and then stored at $4^{\circ} \mathrm{C}$ in PBS. Slices were preblocked for $2 \mathrm{~h}$ at room temperature in PBS plus $0.2 \%$ BSA and $5 \%$ normal goat serum, then incubated at $4^{\circ} \mathrm{C}$ with a rabbit anti-tyrosine hydroxylase (TH) polyclonal antibody (1:100). Slices were then washed thoroughly in PBS with $0.2 \%$ BSA before being agitated overnight at $4^{\circ} \mathrm{C}$ with $\mathrm{Cy} 5$ anti-rabbit secondary antibody (1:100) and FITC streptavidin $(6.5 \mu \mathrm{l} / \mathrm{ml})$. Sections were rinsed and mounted on slides using Bio-Rad Fluoroguard Antifade Reagent mounting media and visualized under a Zeiss LSM 510 META microscope. Primary antibodies were obtained from Millipore Bioscience Research Reagents, secondary antibodies from Jackson ImmunoResearch Laboratories, and all other reagents from Sigma.

A hyperpolarization in response to bath application of the $\kappa$-opioid receptor (KOP-R) agonist (+)- $(5 \alpha, 7 \alpha, 8 \beta)-N$-methyl- $N$-[7-(1pyrrolidinyl)-1-oxaspiro[4.5]dec-8-yl]benzeneacetamide (U69593; 1

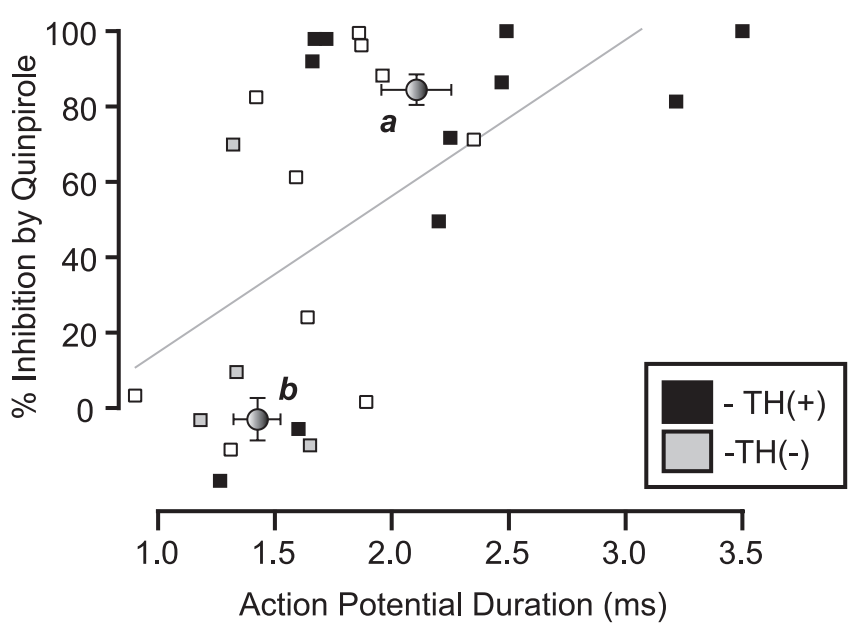

Figure 1. Action potential duration is correlated with $\mathrm{D}_{2} \mathrm{R}$ agonist inhibition in VTA neurons. Spontaneously firing VTA neurons from uninjected animals were tested for responses to bathapplied $1 \mu \mathrm{m}$ quinpirole. Open symbols represent neurons in which TH content was not determined. " $a$ " indicates the means \pm SEM among neurons significantly inhibited by quinpirole, and " $b$ " indicates the means \pm SEM among neurons not inhibited by quinpirole.

$\mu \mathrm{M}$ ) was also taken as an indication that a neuron was DA (Margolis et al., 2003) except in experiments testing AMYG-projecting neurons for KOP-R sensitivity, in which immunocytochemical identification was required.

Data analysis. At least 10 APs from each neuron were averaged together, and the resulting trace was measured between when the membrane potential $\left(V_{\mathrm{m}}\right)$ crossed threshold (when the slope of the $V_{\mathrm{m}}$ first exceeded $5 \mathrm{~V} / \mathrm{s}$ ) to when the $V_{\mathrm{m}}$ recrossed the threshold after the AP peak.

Results are presented as mean \pm SEM where appropriate. Differences between NAc, PFC, and AMYG projection populations were tested using a one-way ANOVA followed by the Bonferroni $t$ test for pairwise multiple comparisons. Drug effects were statistically evaluated by comparing the last eight baseline data points to the last eight data points during drug application using Student's unpaired $t$ test. $p<0.05$ was required for significance in all analyses.

\section{Results}

\section{AP duration correlates with $\mathrm{D}_{2} \mathrm{R}$ inhibition}

A significant correlation between AP duration and $\mathrm{D}_{2} \mathrm{R}$ mediated inhibition in VTA neurons has recently been reported in vivo (Roesch et al., 2007). Therefore we asked whether this correlation exists in vitro. We measured spontaneously occurring APs and pharmacological responses in current-clamp mode in VTA neurons from control rats. DA neurons were identified by filling recorded cells with biocytin and then immunocytochemically processing them for TH content. Among randomly selected neurons, we confirmed a significant positive correlation between longer AP duration and the presence of $\mathrm{D}_{2} \mathrm{R}$ agonist inhibition (Spearman rank order correlation, $p<0.001$ ) (Fig. 1). However, consistent with previous in vitro data (Johnson and North, 1992), neither AP duration nor $\mathrm{D}_{2} \mathrm{R}$ sensitivity correlated with $\mathrm{TH}$ content.

\section{Action potential duration correlates with projection target}

To examine whether AP duration sorts by projection target, we injected the fluorescent retrograde tracer DiI into one of three VTA projection targets: the NAc, PFC, or AMYG. One week later, we recorded from retrogradely labeled neurons (for injection sites, see supplemental Fig. 1, available at www.jneurosci.org as supplemental material; for recording locations, see supplemental Fig. 2, available at www.jneurosci.org as supplemental material). We found that the AP durations of $\mathrm{TH}(+)$ VTA neurons vary 
A

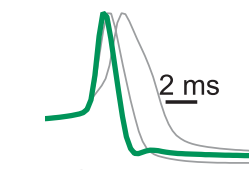

AMYG-projecting

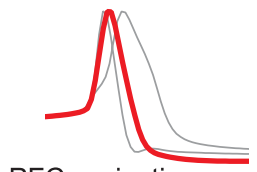

PFC-projecting

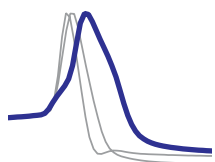

NAc-projecting
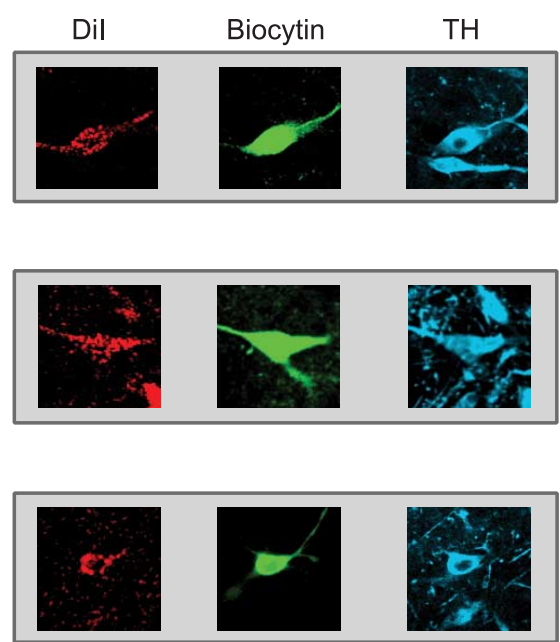

B

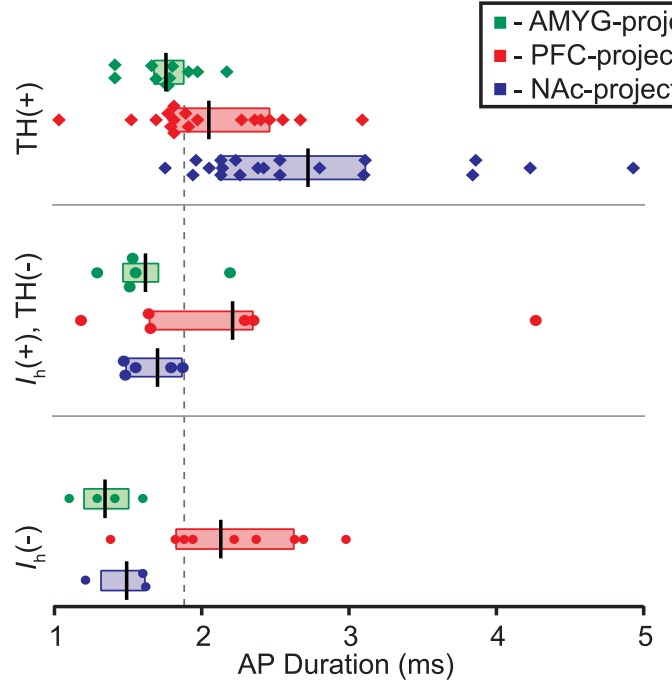

Figure 2. Amygdala-projecting VTA DA neurons have short duration action potentials. A, Example APs collected from neurons that project to the AMYG, PFC, or NAC with the corresponding immunocytochemistry. Neurons were labeled by the retrograde marker Dil (red), filled with biocytin during the recording (green), and immunocytochemically identified as $\mathrm{TH}(+)$ (blue). $\boldsymbol{B}$, The distribution of AP durations in confirmed $\mathrm{TH}(+)$ neurons (top), $I_{\mathrm{h}}(+)$, $\mathrm{TH}(-)$ neurons (middle), and $I_{\mathrm{h}}(-)$ neurons (bottom) for each projection target. Rectangles represent the 25 th and 75 th percentiles of each sample, the solid black vertical lines indicate the means, and the broken gray line at $1.87 \mathrm{~ms}$ is the longest AP duration recorded in an NAc-projecting TH(-) neuron.

with projection target (Fig. 2; supplemental Table 1, available at www.jneurosci.org as supplemental material). Among $\mathrm{TH}(+)$ VTA neurons, AMYG-projecting cells exhibited the briefest AP durations, and they were significantly shorter than those of NAcprojecting cells. The APs of $\mathrm{TH}(+)$ VTA neurons projecting to the PFC were also significantly briefer than NAc-projecting $\mathrm{TH}(+)$ neurons, but tended to be longer than those of AMYGprojecting neurons.

We also examined $\mathrm{TH}(-)$ VTA neurons. These included both $I_{\mathrm{h}}(+)$ and $I_{\mathrm{h}}(-)$ neurons in each of the three projection populations. Among NAc-projecting neurons, the mean AP durations of both $I_{\mathrm{h}}(-)$ and $I_{\mathrm{h}}(+) \mathrm{TH}(-)$ neurons were significantly shorter in duration than those of $\mathrm{TH}(+)$ neurons. There was a relatively small overlap in the distributions of NAc-projecting $\mathrm{TH}(+)$ and either type of $\mathrm{TH}(-)$ neurons (Fig. 2 B; supplemental Table 1, available at www.jneurosci.org as supplemental material). The AP durations of AMYG-projecting $\mathrm{TH}(-)$ neurons were also shorter than AMYG-projecting $\mathrm{TH}(+)$ neurons (Fig. $2 \mathrm{~B}$ ). In contrast, the distributions of AP durations among all three types of PFC-projecting neurons were similar (Fig. $2 \mathrm{~B}$; supplemental Table 1, available at www.jneurosci.org as supplemental material). Importantly, the AP durations of AMYG-projecting $\mathrm{TH}(+)$ neurons were briefer than many NAc- or PFC-projecting $\mathrm{TH}(-)$ neurons.

\section{Inhibition by $D_{2} R$ activation sorts by projection target}

Given that randomly selected neurons with short duration AP neurons are not inhibited by $\mathrm{D}_{2} \mathrm{R}$ activation, we hypothesized that AMYG-projecting neurons should not be inhibited by $D_{2} R$ agonists. Indeed, none of the seven tested AMYG-projecting $\mathrm{TH}(+)$ neurons were hyperpolarized by $1 \mu \mathrm{M}$ quinpirole. Further, only 3 of 23 AMYG-projecting neurons were significantly hyperpolarized by quinpirole; in fact, there was a slight trend among AMYG-projecting $\mathrm{TH}(+)$ neurons for quinpirole to be depolarizing (supplemental Table 2, available at www. jneurosci.org as supplemental material). As a positive control, the $\mathrm{GABA}_{\mathrm{B}}$ agonist baclofen $(1 \mu \mathrm{M})$ yielded a robust hyperpolarization in neurons not hyperpolarized by quinpirole (five of six neurons) (Fig. 3Ai). In addition, there was no response to the $\mathrm{D}_{2} \mathrm{R}$ antagonist sulpiride $(10 \mu \mathrm{M})$ in these cells $(1.0 \pm 1.1 \mathrm{mV} ; n=3)$, ruling out the possibility that this lack of hyperpolarization in response to quinpirole was caused by tonic activation of $\mathrm{D}_{2} \mathrm{Rs}$ by endogenously released DA. In contrast, most PFC- (78\%) and NAc- $(69 \%)$ projecting $\mathrm{TH}(+)$ neurons did exhibit significant hyperpolarizations in response to quinpirole (Fig. $3 B$, $C$; supplemental Table 2, available at www.jneurosci.org as supplemental material).

Similar to our findings for PFC-projecting, but not NAcprojecting, VTA DA neurons (Margolis et al., 2006a), AMYGprojecting $\mathrm{TH}(+)$ neurons were hyperpolarized by the KOP-R selective agonist U69593 (1 $\mu \mathrm{M})$ (Fig. 3Aii).

To examine the possibility that the unique and unexpected properties of AMYG-projecting DA neurons are related to the developmental stage of our rats [postnatal day 33 (P33)-P35 when they were killed] (Grace et al., 2007), we repeated our AP duration and quinpirole experiments in AMYG-projecting VTA neurons in older rats (200 $\pm 5 \mathrm{~g}$ at surgery). Recordings were completed 8-9 d after surgery. Consistent with our findings in younger animals, quinpirole did not hyperpolarize any of the seven tested AMYG-projecting neurons, including four confirmed as $\mathrm{TH}(+)$. Furthermore, the AP durations of $\mathrm{TH}(+)$ AMYG-projecting DA neurons were consistently shorter (1.95 \pm $0.09 \mathrm{~ms} ; n=5)$ than other VTA DA neurons, yet still longer than those of $\mathrm{TH}(-)$ AMYG-projecting neurons (supplemental Table 1, available at www.jneurosci.org as supplemental material). Therefore there were no changes in these properties in the VTA over the course of adolescence.

\section{Discussion}

We show here that $\mathrm{AP}$ duration and $\mathrm{D}_{2} \mathrm{R}$ agonist responses in VTA neurons sort by projection target. In vivo recordings typically presume $\mathrm{TH}$ content based on $\mathrm{AP}$ duration and $\mathrm{D}_{2} \mathrm{R}$ agonist response. However, our results show that the use of these criteria to identify VTA DA neurons will lead to a sample that not only includes a significant number of non-DA neurons but, equally important, excludes many DA neurons. In particular, when using both of these markers, DA neurons that project to the NAc will be 
A

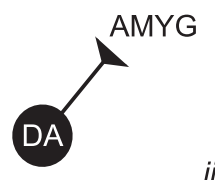

ii

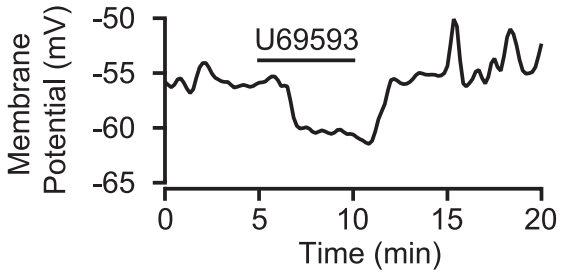

B

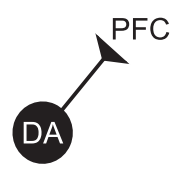

C
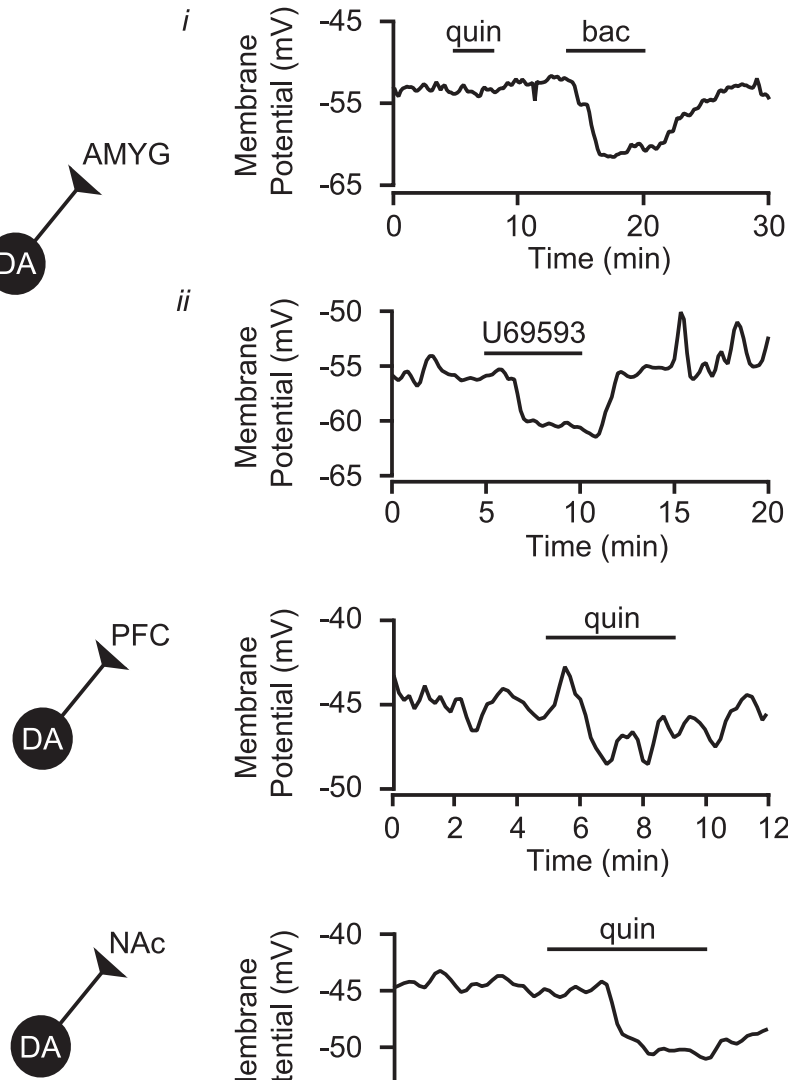

\begin{tabular}{r|c|c|}
\multicolumn{1}{c}{} & D2 & no D2 \\
\cline { 2 - 3 } All & 3 & 20 \\
\hline $\mathrm{TH}(+)$ & 0 & 7 \\
\hline $\mathrm{TH}(-)$ & 2 & 5 \\
\cline { 2 - 3 } & &
\end{tabular}

\begin{tabular}{r|c|c|}
\multicolumn{1}{c}{} & \multicolumn{1}{c|}{$\kappa$} & no $\kappa$ \\
\cline { 2 - 3 } All & 9 & 2 \\
\hline $\mathrm{TH}(+)$ & 3 & 0 \\
\cline { 2 - 3 } & &
\end{tabular}

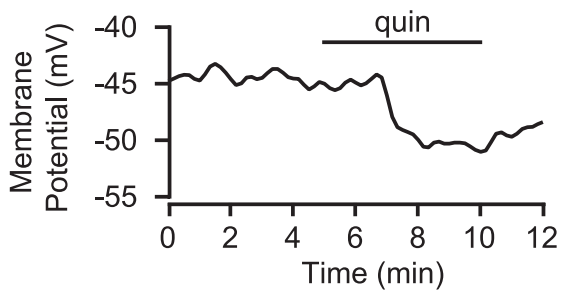

neurons will depend strongly on the experimental conditions; electrode properties, filter settings, and amplifier design will all affect AP duration measurements. Regardless, the consistencies between our work and in vivo studies indicate that the relative patterns described in this report are likely to hold for other preparations.

Our results differ sharply from those recently reported in mouse VTA. For instance, in the mouse, $\mathrm{D}_{2} \mathrm{R}$-mediated hyperpolarizations are not present in PFCprojecting neurons (Lammel et al., 2008), but are present in AMYG-projecting VTA neurons (Ford et al., 2006; Lammel et al., 2008). We show here that in the rat PFCprojecting but not AMYG-projecting neurons are hyperpolarized by $\mathrm{D}_{2} \mathrm{R}$ agonists. In the mouse, the AP durations of NAcprojecting neurons are shorter than those in AMYG-projecting neurons (Lammel et al., 2008), unlike our current findings in the rat. The $I_{\mathrm{h}}$ is absent in mouse PFCprojecting VTA DA neurons (Lammel et al., 2008), but is large in rat PFCprojecting DA neurons (Margolis et al., 2006a). Also in the mouse, many NAcprojecting neurons, but not AMYGprojecting neurons, are inhibited by KOP-R agonists (Ford et al., 2006). In the rat AMYG-projecting DA neurons are inhibited by KOP-R agonists (Fig. 3Aii), but NAc-projecting DA neurons are not (Margolis et al., 2006a). These differences indicate that the properties of different populations of VTA DA neurons do not generalize between species. Importantly, they also indicate that different subpopu-

Amygdala-projecting VTA neurons are not hyperpolarized by $\mathrm{D}_{2} \mathrm{R}$ activation. Ai, Example AMYG-projectir VTA neuron: $1 \mu \mathrm{m}$ quinpirole (quin) application did not modulate the membrane potential; however, $1 \mu \mathrm{m}$ of the $\mathrm{GABA}_{B}$ recepto agonist baclofen (bac) hyperpolarized the cell. Aii, Example AMYG-projecting neuron hyperpolarized by the KOP-R agonist U69593 (1 $\mu \mathrm{M}$ ). B, C, Example PFC-projecting (B) and NAc-projecting (C) TH(+) VTA neurons hyperpolarized by $1 \mu \mathrm{m}$ quinpirole. Tables indicate the number of neurons hyperpolarized or not in each projection.

overrepresented in the sample, whereas AMYG-projecting DA neurons will be uniformly excluded.

The majority of recordings reported here were from adolescent rats. Although neural properties in older rats may be different, our in vitro data are consistent with previous in vivo studies in adult rats in which researchers used antidromic stimulation to identify projection target and conduction velocity to identify putative DA neurons for both NAc-projecting (Yim and Mogenson, 1980) and PFC-projecting (Shepard and German, 1984) VTA neurons. Specifically, Mogenson and colleagues showed that AP duration sorts with presumed DA content among NAcprojecting VTA neurons (Maeda and Mogenson, 1982), and that $89 \%$ of putative DA neurons and $40 \%$ of putative non-DA neurons that project to the NAc are inhibited by $\mathrm{D}_{2} \mathrm{R}$ activation (Yim and Mogenson, 1980). These numbers are similar to our proportions of NAc-projecting quinpirole-responsive neurons (Fig. 3). Although there are no published in vivo data on the properties of AMYG-projecting VTA neurons to which we can compare our findings, the consistencies between the properties measured at two developmental time points here suggest stable neural properties in this projection. Our data are also consistent with a recent in vivo report of "novel" rat VTA neurons including $\mathrm{TH}(+)$ neurons with shorter duration APs and $\mathrm{TH}(-)$ neurons inhibited by quinpirole (Luo et al., 2008). It is important to note that the exact values determined for AP duration of different populations of

lations of VTA neurons will be isolated in the mouse and the rat if AP duration and $\mathrm{D}_{2} \mathrm{R}$ agonist responses are used as identification criteria. Therefore the emerging differences between mice and rats caution against generalizing findings between species, in particular with respect to VTA neuronal properties.

We propose that a major step to improve the interpretation of in vivo electrophysiological data collected in the VTA is to sample all VTA neurons, identifying projection target wherever possible (Yim and Mogenson, 1980; Melis et al., 2000). In addition, projection target identification will allow the investigator to determine whether a VTA neuron is DA-containing with much greater reliability (Fig. 4). For instance, our present data suggest that among NAc-projecting neurons the probability is 1.0 that a neuron is $\mathrm{TH}(+)$ if its AP duration is greater than the median of the NAc-projecting population. Even among AMYG-projecting neurons with much shorter AP durations overall, the probability is 0.82 that a neuron is $\mathrm{TH}(+)$ if its AP duration is greater than the median. Finally, a PFC-projecting VTA neuron that is inhibited by a $\mathrm{D}_{2} \mathrm{R}$ agonist has a 0.88 probability of being $\mathrm{TH}(+)$ based on our current data. Postsynaptic inhibition by a KOP-R agonist may prove to be an even more accurate pharmacological tool for identifying $\mathrm{TH}(+)$ neurons among PFC-projecting VTA neurons, because KOP-R agonists inhibited $100 \%$ of tested PFCprojecting $\mathrm{TH}(+)$ neurons (Margolis et al., 2006a).

One major functional implication of these findings is that 
local DA release in the VTA, from either dendrites or axon collaterals (Bayer and Pickel, 1990), will differentially modulate neighboring populations of VTA neurons with different projection targets and neurotransmitter content. That is, whereas NAc- and PFC-projecting VTA DA neurons will be directly inhibited by local DA release, AMYG-projecting DA neurons will not. KOP-R agonists will postsynaptically inhibit a different subset of VTA neurons: DA neurons that project to the PFC and AMYG, but not those that project to the NAc (Margolis et al., 2006a). Such combinations of postsynaptic effects provide a mechanism by which distinct subsets of VTA neurons can be activated or inhibited.

Researchers have reported that in rats and monkeys there is a common neural discharge pattern among long-duration AP neurons in the VTA. These neurons fire in response to novel stimuli, unexpected reward, and reward-predictive cues, and in a pattern consistent with a reward expectancy error signal (Hyland et al., 2002; Fields et al., 2007; Schultz, 2007). Experiments using fast scan cyclic voltammetry detection of DA release in the NAc also support the hypothesis that at least some of the neurons exhibiting these firing patterns are DA neurons that project to the NAc (Phillips et al., 2003; Roitman et al., 2004; Day et al., 2007). Our present findings indicate that many neurons with longduration APs are in fact NAc-projecting DA neurons. However, because most investigators making in vivo recordings during behavioral tasks have excluded neurons that do not have very longduration APs, firing patterns of VTA DA neurons with shorter duration APs that project to nonstriatal targets are unknown. It is possible that such neurons have firing patterns distinct from those of NAc-projecting DA neurons. In view of the critical roles of DA release in a variety of important functions including working memory (Phillips et al., 2008), learning, motivation, and reinforcement (Fields et al., 2007), and that the dysfunction of midbrain DA neurons contributes to disease states such as schizophrenia (Sesack and Carr, 2002), attention deficit hyperactivity disorder (Viggiano et al., 2003), and drug addiction (Lüscher and Ungless, 2006), it is essential that we have a more complete understanding of the firing patterns of all classes of VTA DA neurons. Here we show that determining the projection target of VTA neurons increases the accuracy of DA neuron identification in addition to the inherent value of knowing the connectivity of the neuron in question. Consequently, this approach has the potential to provide insight into how different subpopulations of VTA neurons contribute to reward, motivation, and several common disease states.

\section{References}

Aghajanian GK, Bunney BS (1977) Pharmacological characterization of dopamine "autoreceptors" by microiontophoretic single-cell recording studies. Adv Biochem Psychopharmacol 16:433-438.

Alderson HL, Latimer MP, Winn P (2006) Intravenous self-administration of nicotine is altered by lesions of the posterior, but not anterior, pedunculopontine tegmental nucleus. Eur J Neurosci 23:2169-2175. PFC-projecting neurons.
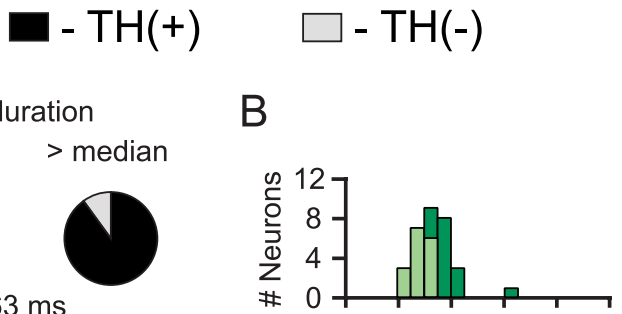

C D2R inhibited

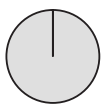

$1.63 \mathrm{~ms}$
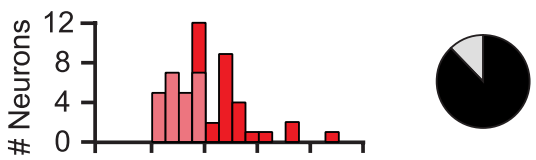

$1.92 \mathrm{~ms}$
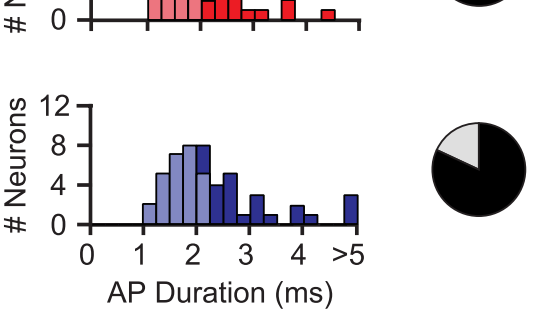

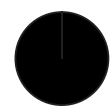

$2.13 \mathrm{~ms}$
AP Duration (ms)

Figure 4. AP duration identifies $\mathrm{TH}(+)$ neurons in AMYG- and NAc-projecting VTA populations. $\boldsymbol{A}, \mathrm{A}$ median split of the AP durations was made within each projection population among immunocytochemically identified neurons. Among AMYG- and

Bayer HM, Glimcher PW (2005) Midbrain dopamine neurons encode a quantitative reward prediction error signal. Neuron 47:129-141.

Bayer VE, Pickel VM (1990) Ultrastructural localization of tyrosine hydroxylase in the rat ventral tegmental area: relationship between immunolabeling density and neuronal associations. J Neurosci 10:2996-3013.

Bunney BS, Walters JR, Roth RH, Aghajanian GK (1973a) Dopaminergic neurons: effect of antipsychotic drugs and amphetamine on single cell activity. J Pharmacol Exp Ther 185:560-571.

Bunney BS, Aghajanian GK, Roth RH (1973b) Comparison of effects of L-dopa, amphetamine and apomorphine on firing rate of rat dopaminergic neurones. Nat New Biol 245:123-125.

Day JJ, Roitman MF, Wightman RM, Carelli RM (2007) Associative learning mediates dynamic shifts in dopamine signaling in the nucleus accumbens. Nat Neurosci 10:1020-1028.

Deniau JM, Thierry AM, Feger J (1980) Electrophysiological identification of mesencephalic ventromedial tegmental (VMT) neurons projecting to the frontal cortex, septum and nucleus accumbens. Brain Res 189:315-326.

El-Amamy H, Holland PC (2007) Dissociable effects of disconnecting amygdala central nucleus from the ventral tegmental area or substantia nigra on learned orienting and incentive motivation. Eur J Neurosci 25:1557-1567.

Fallon JH (1981) Collateralization of monoamine neurons: mesotelencephalic dopamine projections to caudate, septum, and frontal cortex. J Neurosci 1:1361-1368.

Fields HL, Hjelmstad GO, Margolis EB, Nicola SM (2007) Ventral tegmental area neurons in learned appetitive behavior and positive reinforcement. Annu Rev Neurosci 30:289-316.

Ford CP, Mark GP, Williams JT (2006) Properties and opioid inhibition of mesolimbic dopamine neurons vary according to target location. J Neurosci 26:2788-2797.

Grace AA, Bunney BS (1980) Nigral dopamine neurons: intracellular recording and identification with L-dopa injection and histofluorescence. Science 210:654-656.

Grace AA, Onn SP (1989) Morphology and electrophysiological properties of immunocytochemically identified rat dopamine neurons recorded in vitro. J Neurosci 9:3463-3481.

Grace AA, Floresco SB, Goto Y, Lodge DJ (2007) Regulation of firing of dopaminergic neurons and control of goal-directed behaviors. Trends Neurosci 30:220-227. 
Groves PM, Wilson CJ, Young SJ, Rebec GV (1975) Self-inhibition by dopaminergic neurons. Science 190:522-528.

Hyland BI, Reynolds JN, Hay J, Perk CG, Miller R (2002) Firing modes of midbrain dopamine cells in the freely moving rat. Neuroscience 114:475-492.

Ikemoto S, Qin M, Liu ZH (2006) Primary reinforcing effects of nicotine are triggered from multiple regions both inside and outside the ventral tegmental area. J Neurosci 26:723-730.

Johnson SW, North RA (1992) Two types of neurone in the rat ventral tegmental area and their synaptic inputs. J Physiol 450:455-468.

Jones S, Kauer JA (1999) Amphetamine depresses excitatory synaptic transmission via serotonin receptors in the ventral tegmental area. J Neurosci 19:9780-9787.

Korotkova TM, Sergeeva OA, Eriksson KS, Haas HL, Brown RE (2003) Excitation of ventral tegmental area dopaminergic and nondopaminergic neurons by orexins/hypocretins. J Neurosci 23:7-11.

Lacey MG, Mercuri NB, North RA (1987) Dopamine acts on D2 receptors to increase potassium conductance in neurones of the rat substantia nigra zona compacta. J Physiol 392:397-416.

Lacey MG, Mercuri NB, North RA (1989) Two cell types in rat substantia nigra zona compacta distinguished by membrane properties and the actions of dopamine and opioids. J Neurosci 9:1233-1241.

Lammel S, Hetzel A, Häckel O, Jones I, Liss B, Roeper J (2008) Unique properties of mesoprefrontal neurons within a dual mesocorticolimbic dopamine system. Neuron 57:760-773.

Luo AH, Georges FE, Aston-Jones GS (2008) Novel neurons in ventral tegmental area fire selectively during the active phase of the diurnal cycle. Eur J Neurosci 27:408-422.

Lüscher C, Ungless MA (2006) The mechanistic classification of addictive drugs. PLoS Med 3:e437.

Maeda H, Mogenson GJ (1982) Effects of peripheral stimulation on the activity of neurons in the ventral tegmental area, substantia nigra and midbrain reticular formation of rats. Brain Res Bull 8:7-14.

Margolis EB, Hjelmstad GO, Bonci A, Fields HL (2003) $\kappa$-Opioid agonists directly inhibit midbrain dopaminergic neurons. J Neurosci 23:9981-9986.

Margolis EB, Lock H, Chefer VI, Shippenberg TS, Hjelmstad GO, Fields HL (2006a) Kappa opioids selectively control dopaminergic neurons projecting to the prefrontal cortex. Proc Natl Acad Sci U S A 103:2938-2942.

Margolis EB, Lock H, Hjelmstad GO, Fields HL (2006b) The ventral tegmental area revisited: is there an electrophysiological marker for dopaminergic neurons? J Physiol 577:907-924.
Melis M, Gessa GL, Diana M (2000) Different mechanisms for dopaminergic excitation induced by opiates and cannabinoids in the rat midbrain. Prog Neuropsychopharmacol Biol Psychiatry 24:993-1006.

Nair-Roberts RG, Chatelain-Badie SD, Benson E, White-Cooper H, Bolam JP, Ungless MA (2008) Stereological estimates of dopaminergic, GABAergic and glutamatergic neurons in the ventral tegmental area, substantia nigra and retrorubral field in the rat. Neuroscience 152:1024-1031.

Phillips PE, Stuber GD, Heien ML, Wightman RM, Carelli RM (2003) Subsecond dopamine release promotes cocaine seeking. Nature 422:614-618.

Phillips AG, Vacca G, Ahn S (2008) A top-down perspective on dopamine, motivation and memory. Pharmacol Biochem Behav 90:236-249.

Prensa L, Parent A (2001) The nigrostriatal pathway in the rat: a single-axon study of the relationship between dorsal and ventral tier nigral neurons and the striosome/matrix striatal compartments. J Neurosci 21:7247-7260.

Roesch MR, Calu DJ, Schoenbaum G (2007) Dopamine neurons encode the better option in rats deciding between differently delayed or sized rewards. Nat Neurosci 10:1615-1624.

Roitman MF, Stuber GD, Phillips PE, Wightman RM, Carelli RM (2004) Dopamine operates as a subsecond modulator of food seeking. J Neurosci 24:1265-1271.

Schultz W (2007) Behavioral dopamine signals. Trends Neurosci 30:203-210.

Sesack SR, Carr DB (2002) Selective prefrontal cortex inputs to dopamine cells: implications for schizophrenia. Physiol Behav 77:513-517.

Shepard PD, German DC (1984) A subpopulation of mesocortical dopamine neurons possesses autoreceptors. Eur J Pharmacol 98:455-456.

Swanson LW (1982) The projections of the ventral tegmental area and adjacent regions: a combined fluorescent retrograde tracer and immunofluorescence study in the rat. Brain Res Bull 9:321-353.

Ungless MA, Magill PJ, Bolam JP (2004) Uniform inhibition of dopamine neurons in the ventral tegmental area by aversive stimuli. Science 303:2040-2042.

Viggiano D, Vallone D, Ruocco LA, Sadile AG (2003) Behavioural, pharmacological, morpho-functional molecular studies reveal a hyperfunctioning mesocortical dopamine system in an animal model of attention deficit and hyperactivity disorder. Neurosci Biobehav Rev 27:683-689.

Yim CY, Mogenson GJ (1980) Electrophysiological studies of neurons in the ventral tegmental area of Tsai. Brain Res 181:301-313. 